\title{
REPRESENTAÇÕES DA ENFERMAGEM NA IMPRENSA DA CRUZ VERMELHA BRASILEIRA (1942-1945)
}

\author{
Márcia Cristina da Cruz Mecone ${ }^{1}$, Genival Fernandes de Freitas ${ }^{2}$
}

\footnotetext{
${ }^{1}$ Mestranda do Programa de Pós-Graduação da Escola de Enfermagem da Universidade de São Paulo (USP). São Paulo, Brasil. E-mail: marciamecone@yahoo.com.br

${ }^{2}$ Doutor em Enfermagem. Professor Doutor da Escola de Enfermagem da USP. São Paulo, Brasil. E-mail: genivalf@usp.br
}

\begin{abstract}
RESUMO: O trabalho objetivou identificar o perfil da mulher/enfermeira e analisar representações da enfermagem no contexto da americanização na imprensa escrita. As fontes utilizadas foram imagens e entrevistas publicadas na Revista da Cruz Vermelha Brasileira durante a Segunda Guerra Mundial (1942-1945) sob os auspícios da era varguista. Os achados foram analisados segundo os pressupostos da História Social, valorizando as singularidades e cotidianidades dos indivíduos ou grupos sociais e ampliando a reflexão sobre o contexto sociopolítico. Por meio desta análise pode-se inferir que as imagens, bem como os artigos veiculados na revista supracitada, evidenciavam as enfermeiras como heroínas, patrióticas, "anjos cuidadores", adjetivos usados em apoio ou em adesão social massificada à guerra e, não obstante, ao governo ditatorial de Getúlio Vargas (1930-1945). Entendemos que refletir sobre o passado da enfermagem implica não somente evocar a memória do cuidado, mas perceber a trajetória da identidade profissional.
\end{abstract}

DESCRITORES: História da enfermagem. Imprensa. Cruz Vermelha.

\section{REPRESENTATIONS OF NURSING IN THE PRESS OF THE BRAZILIAN RED CROSS (1942-1945)}

\begin{abstract}
This study aimed to identify the profile of the woman/nurse and analyze representations of nursing in the context of Americanization in the press. The sources used were images and interviews published in the Journal of the Brazilian Red Cross during the Second World War (1942-1945) under the auspices of the Vargas era. The findings were analyzed according to the assumptions of social history, highlighting the singularities and daily lives of individuals or social groups and amplifying reflection on the sociopolitical context. Through this analysis we can infer that the images, as well as the articles published in the journal cited above, show nurses to be heroes: patriotic and "Angel caregivers" by using supportive adjectives or those of social adhesion "massified" to war, and at the same time to the dictatorial Getúlio Vargas government (1930-1945). We believe that reflecting on Nursing's past implies not only to evoke the memory of care, but to better understand the history of professional identity.
\end{abstract}

DESCRIPTORS: History of nursing. Press. Red Cross.

\section{REPRESENTACIONES DE LA ENFERMERÍA EN LA PRENSA DE LA CRUZ ROJA BRASILEÑA (1942-1945)}

RESUMEN: El estudio tuvo como objetivo identificar el perfil de la mujer/enfermera y analizar las representaciones de la enfermería en el contexto de la americanización de la prensa. Las fuentes utilizadas fueron las imágenes y entrevistas publicadas en la Revista de la Cruz Roja Brasileña durante la Segunda Guerra Mundial (1942-1945) bajo los auspicios de la era Vargas. Los resultados fueron analizados de acuerdo a los postulados de la historia social, destacando la singularidad y la vida cotidiana de los individuos o grupos sociales, y centrando la reflexión sobre el contexto sociopolítico. A través del análisis podemos inferir que las imágenes y los informes publicados en la revista citada, muestran a las enfermeras como héroinas, patriotas, o "ángeles cuidadores", adjetivos que son empleados en apoyo o como una adhesión de la sociedad en general a la guerra, pero también, al gobierno dictatorial de Getúlio Vargas (1930-1945). Creemos que reflexionar sobre el pasado de la enfermería no sólo significa evocar la memoria de la atención, sino también percibir la historia de la identidad profesional.

DESCRIPTORES Historia de la enfermería. Prensa. Cruz Roja. 


\section{INTRODUÇÃO}

Registros escritos, imagéticos e relatos verbais possibilitaram o acompanhamento das representações da prática do cuidar e sua trajetória. Espaços temporais e grandes feitos épicos, de acordo com a História, estão envoltos em guerras, cujos desdobramentos revelam o quão é inerente a presença do cuidador junto a soldados feridos ou populações atingidas. Assim, a historiografia tem demarcado as guerras tanto cronologicamente, quanto contextualmente e como acontecimentos destacados, sobretudo do século XX, ao referir-se ao pré-guerra, à guerra propriamente instalada, entre-guerra ou pós-guerra. ${ }^{1}$

O cuidar, desde os primórdios, teve sua trajetória demarcada pela sobrevivência dos povos. As Expedições organizadas pelos cristãos, a partir do final do século XI, Cruzadas, influenciaram o cuidado no entorno dos feridos nas lutas pela recuperação da Terra Santa, Jerusalém, dominada pelos muçulmanos. Senhores feudais e Igreja, com ajuda da população, construíram hospitais, instalaram grande número de mongesmilitares para cuidar de pessoas com ferimentos e doenças. Os cuidados estendiam-se não somente aos soldados Cruzados feridos, eram atendidos, também, peregrinos cristãos necessitados, quando em visita à Terra Santa, pois eram perseguidos pelos muçulmanos. Além das Cruzadas, a influência do cristianismo marcou rituais do cuidado na Idade Média (século V ao XVII), destacando-se reformas sócio-culturais e religiosas no período. Ainda que a prática de cuidar não era planejada, tampouco caracterizada como enfermagem profissional, denota-se o papel do cuidador como agente histórico que agia no intuito de promover alívio ao sofrimento humano, e feridos de guerra. ${ }^{2}$

A figura do cuidador, ao longo da história da humanidade, configurou-se na perspectiva religiosa. Suas práticas foram associadas à atividade doméstica, no que diz respeito à divisão sexuada do trabalho. Na antiguidade, cabia à mulher cuidar da habitação e dos filhos, além de feridos e idosos. Como símbolo da fecundidade, a mulher era responsável por todas as tarefas relativas ao nascimento, crianças, doentes e moribundos. Ao homem cabia prover as necessidades do grupo com alimentação, caça, pesca e colheita de frutos. Por suas características físicas, homens deveriam cuidar de feridos durante a guerra, com traumatismos e fraturas, assim como dominar pessoas com alteração comportamental, com agitação ou agressividade. Dessa organização de tarefas surgiu a divisão sexual do trabalho, sendo que até muito tempo depois a mulher permanecia responsável pela maternidade, parto e assistência às crianças, enquanto os homens, no transcurso do tempo, ficaram mais próximos de atividades na saúde, denominadas ortopedia, cirurgia e psiquiatria. ${ }^{2-3}$

Embora a figura do cuidador esteja sempre presente na vigência dos conflitos bélicos, ainda assim não é uma presença explícita, ou seja, sua atuação é representada nessas circunstâncias como coadjuvante, porém necessária à promoção e à manutenção da vida, tornando-se mais visível essa atuação à medida que atende aos interesses do grupo dominante, do ponto de vista sócio-político.

A fim de discutir a trajetória histórica do cuidado em enfermagem no contexto alvo dessa investigação, passamos à discussão de alguns elementos da profissionalização da enfermagem brasileira que julgamos relevantes.

No final do século XIX e primeiras décadas do século XX, o Brasil foi envolvido nos resultados da intitulada Revolução Científico-Tecnológica que ocorria em todo o mundo capitalista, sobretudo, sob a hegemonia das potências industriais da época, Europa e Estados Unidos.

Considerando suas devidas limitações sociais, as cidades mais populosas, São Paulo e Rio de Janeiro foram estimuladas por um novo conceito de modernidade e dinamismo da economia internacional. Resultados da aplicação dessas mais recentes descobertas, alcançaram transformações e aplicabilidade nos mais variados campos dos processos produtivos brasileiro, cabendo destaque ao impacto no desenvolvimento nas áreas da saúde, quais sejam: medicina, farmacologia, higiene e profilaxia, bem como a descoberta da anestesia. ${ }^{4}$

Os avanços tecnológicos impostos às sociedades tradicionais, de economia agrícola resultaram em mudanças necessárias ao modo de vida dessas pessoas, seu hábitos, práticas de produção, consumo, conforme exigia o novo padrão proposto. Neste contexto, a Fundação Rockfeller, em acordo entre o governo vigente e Estados Unidos, implantou ideais de cientificidade, racionalidade e higiene que imperaram sobre as questões culturais do Brasil republicano, que perduraram até o pós-1930. ${ }^{4}$

A Enfermagem, desde o início do século XX, foi alvo de interesses políticos e esteve envolvida com reformas sanitárias. Desde que despertaram as primeiras preocupações em torno da "higienização da nação", as questões sanitárias favoreceram a inserção de estratégias estrangeiras nas reformas 
internas no campo da saúde. É possível perceber o papel relevante que a profissão teve na implantação da modernização da saúde pública brasileira. ${ }^{5}$

A profissionalização da enfermagem no Brasil, já se consolidava desde 1890 na cidade do Rio de Janeiro, com a criação da primeira Escola de Enfermeiros e Enfermeiras do Hospício Nacional de Alienados, atualmente Escola de Enfermagem Alfredo Pinto. A escola foi oficializada pelo Decreto $N^{\circ} 791$, de 27 de setembro de 1890, que determinava a sua criação, a duração do curso de dois anos e a composição do corpo docente. $\mathrm{O}$ ensino era voltado a cuidados com pacientes psiquiátricos, demandado por processos políticos de formação técnica para assistência a estes pacientes. O exercício da Enfermagem no Brasil, até então, era praticado com base na solidariedade humana. ${ }^{3}$

Ao longo da trajetória da enfermagem profissional no Brasil, mas precisamente a partir da década de 1920, houve várias mudanças e conquistas para a profissão, seja no âmbito legal, político, técnico e histórico da enfermagem. O cuidado como prática de sobrevivência, baseado em conhecimento empírico, foi adquirindo um aspecto pautado em um saber científico, regulamentando o campo de práticas organizadas e de controle formal, o que legitimava a enfermagem como profissão estratégica na organização sanitária de saúde. ${ }^{6}$

No Brasil, a década de 1930 é demarcada pelo fim da alternância no poder das forças políticas e econômicas de São Paulo e Minas Gerais, principal atores da chamada política do café do com leite, em que oligarquias agrárias se consolidavam no poder a partir de fraudes eleitorais e conflitos armados. Em 1932, quando Getúlio Vargas tornou-se o presidente do Brasil, implantou-se a ditadura varguista com a consolidação do Estado Novo (1937-1945).

Uma das frentes do governo varguista era influenciada pela americanização nacional, que tinha como ideologia a Política da Boa Vizinhança, cujo termo se referia à aproximação dos laços de dependência cultural e econômica aos Estados Unidos.

A enfermagem teve seu papel demarcado por aquele processo da americanização. Desde o início da década de 1920, a Fundação Rockfeller atuava em parceria com as políticas públicas brasileiras, inclusive no âmbito da saúde. Ainda na década de 1920, a mesma Fundação, em parceria com o Departamento Nacional de Saúde Pública (DNSP), criou uma escola de enfermagem, que em 1925 foi denominada Escola de Enfermagem Anna Nery, tornando-se, em 1931, escola padrão de enfermagem no Brasil, ou seja, modelo de equiparação para as demais escolas de enfermagem.

Vale ressaltar que, essa equiparação eximia a Escola de Enfermagem da Cruz Vermelha, que na época ainda era vinculada ao Ministério da Guerra e a Escola de Enfermagem Alfredo Pinto no Rio de Janeiro, vinculada ao Ministério da Justiça.

No bojo da americanização, a referida Fundação em 1942 também apoiou a criação da Escola de Enfermagem da Universidade de São Paulo, possibilitando novo foco irradiador do ensino da enfermagem no Brasil, além da capital da República, redimensionando a realidade da enfermagem nacional. $^{6-7}$

No início da década de 1940 eclodiu a Segunda Guerra Mundial (1939-1945). O presente estudo aborda os anos de 1942-1945, recorte temporal escolhido para analisar a representação da enfermagem brasileira no bojo do conflito beligerante, bem como a influência americana na enfermagem de guerra. Desta forma, o recorte delimitado justifica-se por destacar os anos de início e término em que o Brasil envolveu-se no conflito como aliado ao bloco estadunidense frente aos imperativos da política alemã.

Ainda que houvesse esforço de combate norte-americano à expansão do Eixo, este não eximia as bases de interesse em uma exploração econômica sistemática em um mundo pacificado. A americanização do Brasil pelos Estados Unidos legitimava a estratégia em "manter o continente como parte de seu mercado". $8: 35$

Os empenhos produzidos pelos dois países tinham em comum os interesses políticos do Brasil e dos Estados Unidos. Para tanto, as negociações se estenderam a diferentes campos como cultural, saúde, agricultura, administração pública, sistema de transporte e educação. Vale lembrar que a política vigente pautava-se nos preceitos da ditadura estadonovista da Era Vargas, ou seja, governo que dentre suas determinações de poder, empreendia acelerar o desenvolvimento industrial do país e exportação de matéria-prima, como a borracha, imprescindível à indústria bélica, o nervo de guerra, além de interesses geográficos, pois o Brasil oferecia estrategicamente espaço para

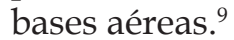

Em outros países, sobretudo os Estados Unidos, historiadores têm pontuado que a perspectiva dos americanos nos cuidados de saúde sofreu profundas modificações no quadro geral da depressão econômica dos anos 1930, seguida pela Segunda Guerra Mundial. Este evento marcou a mudança 
na abordagem dos cuidados privados à saúde, logo, à enfermagem. Líderes de enfermagem nas décadas de 1940 exploraram de forma deliberada a situação e buscaram um novo referencial para a enfermagem. Vale dizer, propulsionou a profissão para uma melhor posição no que tange à educação, padrões de serviço e remuneração, o que significa dizer, suas ações reiteraram tanto a propulsão do saber, ser, conhecer e fazer em enfermagem. Foi criado o Conselho Nacional de Enfermagem para o Serviço de Guerra e uma Comissão voluntária de líderes de enfermagem, composta por enfermeiras, em colaboração com o Serviço de Saúde Pública dos Estados Unidos. A liderança de enfermagem soube como utilizar tais organizações com perspicácia política e alavancar a enfermagem no cenário nacional, redimensionand o o trabalho individual, isolado e fragmentado. ${ }^{10}$

Uma das possibilidades de formação profissional da enfermagem encontra respaldo na Cruz Vermelha. No Brasil, este centro formador vinculado ao Ministério da Guerra, que retomou o ensino na capital paulista, em 1940, foi de crucial importância para o desenvolvimento da enfermagem brasileira. Os cursos de formação em enfermagem tiveram no período uma significativa procura, ocorrendo de forma espontânea, porém alimentado pela influência das propagandas do governo brasileiro, que em discurso persuasivo, projetava a profissão como a imagem de pátria mãe, aquela que proporciona cuidados maternos aos filhos no front. ${ }^{11}$

O discurso hegemônico preconizava a formação técnico-profissional, fundado no ideal de servir ao doente, enfermo, ferido ou com necessidades de cuidado a partir do ideal de mulher que se predispunha a servir a pátria.

No caso da historiografia brasileira, é perceptível a intenção da difusão de uma nova identidade nacional. O Estado Novo caracterizou-se pela cristalização de idéias como patriotismo, unidade nacional, corporativismo, ordem, progresso, culto ao chefe da nação como exemplo a ser seguido. O governo de Getúlio Vargas, ditatorial, tinha como prerrogativa o desenvolvimento de técnicas persuasivas de grande apelo popular, elaboradas para atingir as massas trabalhadoras. É possível sinalizar que a enfermagem brasileira, no período historicamente conhecido como Era Vargas, alcançou um de seus momentos mais marcantes no que diz respeito à procura pela profissão. Pode-se dizer que sua ascensão estava atrelada aos interesses sociopolíticos da época.
A partir dessas premissas, é possível pensar que a enfermagem foi umas das proposições políticas de suma importância no discurso populista a fim de angariar o apoio feminino nas estratégias do governo ditatorial. Sintomaticamente significa dizer que a expansão profissional da enfermagem promoveria a inclusão do feminino do mercado de trabalho, dado a dimensão que as propagandas políticas destacavam o papel da mulher como enfermeira.

Deste modo, a necessidade do olhar crítico sobre o cotidiano, a reflexão no que representa o ser enfermeiro na atualidade, torna-se necessário o questionamento histórico das experiências do passado, bem como suas práticas e representações. Entendemos que estudar a história da enfermagem permite essa reflexão, bem como a proposição de inferências sobre comportamentos, representações e a própria identidade da profissão consolidados no decorrer do tempo, pois referencia questões da prática diária ao interrogar o passado, sobretudo, perspectivas que significaram desigualdades de gênero como aparências, manifestações da sexualidade e luta por direitos nos cotidiano profissionalintelectual. ${ }^{12-13}$ Por conseguinte, algumas problemáticas suscitam questões norteadoras, pois como era o reconhecimento da mulher/enfermeira veiculado pela imprensa sob o cunho da propaganda política em particular a da Cruz Vermelha Brasileira?

\section{OBJETIVO}

Neste sentido, o presente artigo tem como objetivo refletir sobre aspectos da representação da enfermagem face a americanização o Brasil, visando identificar o perfil da mulher/enfermeira na imprensa escrita, especificamente, na Revista da Cruz Vermelha Brasileira durante o envolvimento do Brasil na Segunda Guerra Mundial (1942-1945).

\section{METODOLOGIA}

Para o alcance dos objetivos delineados optouse pela metodologia da História Social, campo na construção do conhecimento histórico que permite a ênfase nas investigações da vida cotidiana que só são percebidas quando examina a documentação em detalhe, valorizando o que os historiadores consideram como a história vinda de baixo. ${ }^{14}$

O material utilizado como fonte primária foi a Revista intitulada Cruz Vermelha Brasileira, especificamente os exemplares de 1942-1945, veiculado pela mesma entidade, compreendida 
como instrumento de grande impacto, sobretudo, na mídia impressa da época, campo político que permite ampliar a reflexão histórica proposta.

Fontes imagéticas e textuais foram selecionadas de acordo com as representações que expressavam, na perspectiva dos investigadores, a visibilidade da enfermagem sob o cunho político social no período delimitado. Assim, foram selecionadas as publicações que evidenciavam a enfermagem como peça importante na mobilização popular, fortalecimento da aliança Brasil - Estados Unidos nos anos em que efetivamente o Brasil participa da guerra enviando soldados e enfermeiras ao front, na Itália.

O trabalho com as imagens permite emersão a respeito das idéias, atitudes e mentalidades de um determinado período. A imagem fotográfica na imprensa, como um fragmento selecionado do real, tem como objetivo retratar fatos verídicos e de fácil aceitação popular. ${ }^{15} \mathrm{~A}$ imprensa não é um veículo que narra ou informa os fatos de forma imparcial, pois o registro do cotidiano deve ser analisado mediante a natureza das fontes, considerando os interesses em jogo. Portanto, o registro do fazer coletivo e das individualidades, conhecida como história imediata, deve ser criticamente examinado, pois a imprensa como fonte não deve ser analisada de maneira simplista ou dicotômica como verdadeiro ou falso, mas como registros passíveis de contextualização. É necessário indagar sobre o que se pretende legitimar como verdade dita. Nessa perspectiva, o desafio do historiador está na desconstrução de como essa verdade foi fabricada e quais foram as condições de sua produção. ${ }^{15-16}$

Foi dispensada a submissão da investigação ao Comitê de Ética em Pesquisa, pois não se trata de pesquisa envolvendo seres humanos, mas de fontes documentais de domínio público e de acervo pessoal dos investigadores.

\section{A MODERNIZAÇÃO DO BRASIL SOB ÓTICA DO MODELO CULTURAL NORTE- AMERICANO}

A política de boa vizinhança dos Estados Unidos, voltada para a americanização da América Latina foi intencionalmente construída, pois coincidia com os interesses da política vigente, visando eliminar o risco de outras ideologias, sobretudo nacionalismo, fascismo, socialismo e comunismo, além dos interesses estratégicos americanos no contexto bélico mundial da década de 1940. Assim, a Segunda Guerra Mundial torna-se o momento crucial na história das relações culturais entre o Brasil e os Estados Unidos. ${ }^{8-17}$

A idéia da política da boa vizinhança incluía a cultura na agenda internacional. A América que, via de regra, precisava aprender as lições do progresso e capitalismo para re-configurar a posição de subdesenvolvimento que, em última instância, precisava projetar-se no capitalismo global. $\mathrm{O}$ americanismo propunha uma integração na área técnico-científica, disseminadora do american way of life, por meio da cultura e propaganda, consideradas matéria-prima tão estratégica como qualquer outro produto de propagação e controle do antiamericanismo. ${ }^{8}$ Cabe pontuar que a intenção dos americanos, de fato, consistia em afastar o risco da ideologia socialista na América do Sul através da imposição do life style dos americanos como mola propulsora para o progresso e civilização. Os ideais eram difundidos nos meios de comunicação de massa, especialmente, a imprensa escrita, o rádio (rádio teatro e rádio jornal) e os filmes hollywoodiano, bem como letras de músicas.

No campo da saúde, especialistas foram enviados dos Estados Unidos à bacia Amazônica para analisar, em cooperação com o governo brasileiro, as condições de saúde e encontrar a melhor forma de combater doenças tropicais e desnutrição. Propagava-se o ideal de que o Brasil tinha muito que aprender com os americanos e, para tanto, a programação de emissoras americanas de onde curtas eram veiculados em português, em diferentes revistas e jornais brasileiros, como parte do esforço de guerra. Nessas propagandas, ressaltava-se a enfermeira visitadora como guardiã e facilitadora dos bons hábitos alimentares, associando-se idéias de legumes, saúde e guerra. ${ }^{5}$

\section{O IMPACTO DA FERRAMENTA ICONO- GRÁFICA NA IMPRENSA: ENFERMA- GEM BRASILEIRA SOB OS AUSPÍCIOS DA ERA VARGAS}

A imprensa foi um importante veículo de formação de opinião à época. Entre as publicações veiculadas e permitidas pelo Departamento de Imprensa e Propaganda, destacavam-se as que faziam alusão às comemorações cívicas, explo-

\footnotetext{
Criado durante o Estado Novo em 1939. Tinha o intuito de censura sobre os meios de comunicação. Seu principal alvo era o controle de informações de qualquer ação contrária aos ideais do Estado.
} 
rando um especial caráter patriótico, exaltador da memória cívica e das quais emerge um dos seus principais personagens: a enfermeira. Era comum deparar-se com a imprensa da época registrando festividades cívicas com fotos de enfermeiras em desfiles pelas ruas das principais cidades, sobretudo, São Paulo e Rio de Janeiro.

Simbolicamente, as estratégias do Estado Novo demonstram a ênfase dada aos ideais militares, quais sejam: disciplina, povo em marcha, bravura, lealdade, destreza, desbravamento, coragem, organização e vigilância, sacrifício e união, palavras de ordem que fabricavam comportamentos, moldavam formas de expressão e pensamento junto a população. A intenção era sensibilizar a nação com imagens cívicas gloriosas - como a exaltação e importância da mulher nos campos de atuação social em favor da paz e contra a guerra - seja por intermédio da enfermagem, atuando diretamente no cuidado, em oficinas de costura, realizando bazares beneficentes, entre outros. ${ }^{18}$

A análise das revistas mencionadas nos permite perceber certa prolixidade quanto à exaltação da enfermagem da época, cabendo a mulher/enfermeira toda a glória pela sua bondade instintiva ao sexo. O que reforça o estereótipo desejado para representar a enfermeira da época. Pode-se dizer, inclusive, que o mesmo ocorre com as imagens muito comum de se perceber em textos escritos e com fotografias, ou seja, são os discursos e imagens que silenciam e estereotipam as mulheres.

Ainda assim, o teor dos registros enaltece a dignidade da profissão com textos sobre a importância da enfermagem destacada pelas reportagens ou propagandas. Do mesmo modo, desvela-se uma representação subserviente e dócil como sendo atributos inerentes à profissão. É possível observar certa importância dada ao carisma das práticas de enfermagem, e não necessariamente atrelado ao conhecimento para exercer tal prática enfatizando, em contrapartida, a intencionalidade de supervalorizar o saber médico. Calcado no poder que emana da institucionalização da medicina, a ampliação do conhecimento científico e do status social e profissional, o médico é representado como detentor único do poder de diagnosticar doenças e determinar a cura, conferindo tal poder à hegemonia, autonomia e cientificidade de suas ações profissionais. ${ }^{3}$

A Figura 1 mostra a presença de autoridades nacionais, bem como as enfermeiras da Cruz Vermelha Brasileira ao descerrar o retrato de Getúlio Vargas, em um ato de reverência ao poder máximo da nação. Trata-se da senhora Carmela Dutra, esposa do Sr. Marechal Eurico Gaspar Dutra, no ato de inauguração do Posto 18 da Cruz Vermelha Brasileira no Rio de Janeiro. ${ }^{18} \mathrm{O}$ momento registrado pelo fotógrafo e o posicionamento congelado na imagem, emanam prerrogativas de culto à personalidade, ao poder vigente, assim como toda a sua esfera de comando, portanto, mais uma vez a presença das enfermeiras representando a importância do seu papel, enquanto personalidade necessária para consolidação de um Estado saudável.

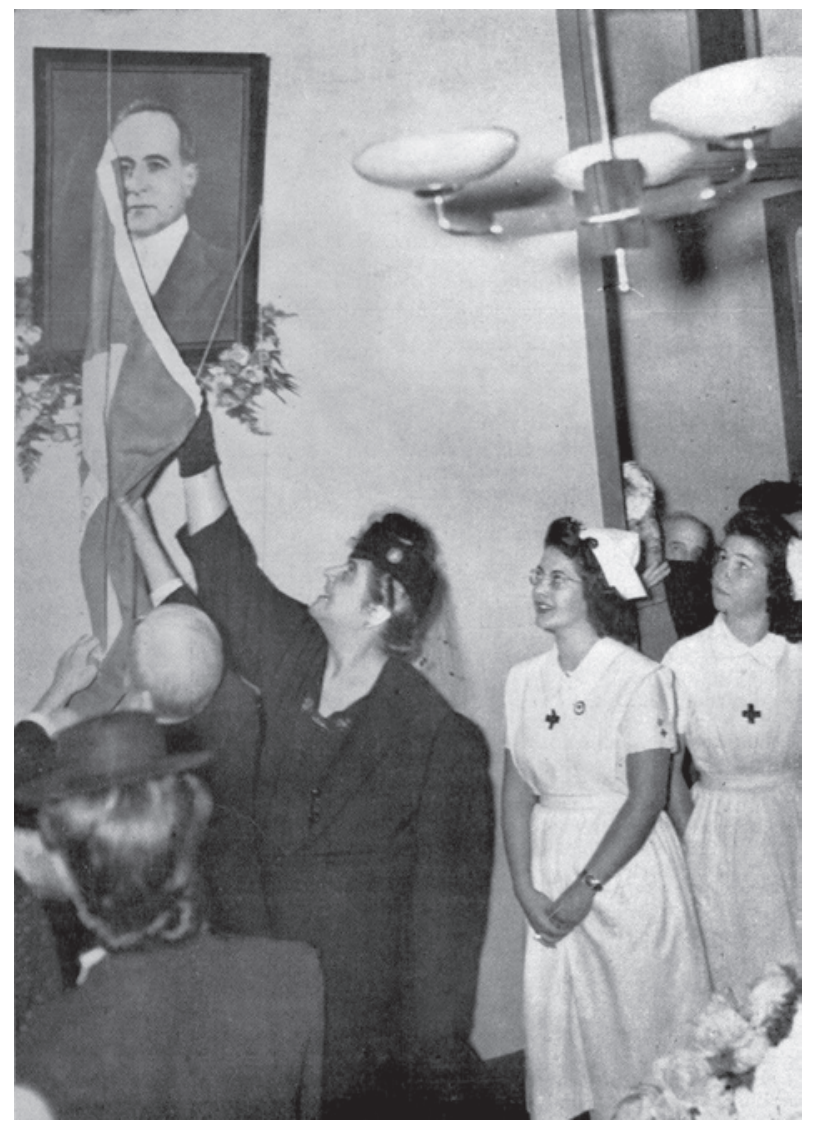

Fonte: Revista da Cruz Vermelha Brasileira. Julho, 1943. p.8

Figura 1 - Inauguração do Posto 18 da Cruz Vermelha Brasileira.

A presença feminina em prol da mobilização popular era ressaltada em vários segmentos da sociedade, sobretudo, eventos beneficentes, que visavam angariar subsídios aos soldados no front de batalha. As propagandas das campanhas da Legião Brasileira de Assistência (LBA) são exemplo dessa benfeitoria. Movimento composto por mulheres dispostas a se integrar nas causas assistenciais de guerra, idealizado pela primeira-dama Darcy Vargas. Entre essas ações estavam preparação para oficinas de costura, a horta da vitória, os livros dos combatentes e as madrinhas dos combatentes. ${ }^{19}$ 
O apoio popular a guerra era uma demonstração de patriotismo, a evidência da política da boa vizinhança instalada pela aliança BrasilEstados Unidos, divulgada como necessária para a "salvaguarda do hemisfério ocidental diante da ameaça nazista". 8:47

A partir do segundo semestre de 1943, a imprensa da Cruz Vermelha Brasileira, periodicamente destaca enquetes com a publicação de recortes das respostas, bem como retratos das entrevistadas, alunas, ex-alunas ou enfermeiras da Cruz Vermelha Brasileira.

As perguntas da entrevista eram em torno da formação profissional dessas mulheres, entre elas: motivação para o ingresso na Cruz Vermelha Brasileira, as perspectivas sobre a participação ativa da mulher na guerra e opinião referente à vontade participar na guerra fora do país.

É possível perceber que a narrativa da reportagem busca construir por meio das respostas das alunas um pensamento de dever a cumprir para com a pátria pelas demais mulheres brasileiras. Fundado num discurso submisso e de auxílio ao próximo, logo, o patriotismo e a reverência aos ideais cívicos. "Sim, na guerra, não há homens nem mulheres. Há soldados para a defesa da Pátria. E somente assim ela poderá ser forte e feliz, por que sabe que todos os seus filhos, sem exceção, não pouparão sacrifícios no tributo do seu amor e da sua gratidão" ${ }^{20: 31}$

Vale ressaltar que abaixo das entrevistas uma nota destacava "Lendo esta revista você colabora no esforço de guerra da Cruz Vermelha Brasileira". 20:31

Em 1945, a carta enviada do front na Itália pelo General Mascarenhas de Morais, ${ }^{* *}$ ao Presidente da Cruz Vermelha Brasileira foi caracterizada como um "documento de alto valor e de justiça". ${ }^{21: 24}$ Nesta correspondência, de agradecimento à entidade, como a instituição que mais se destacou na colaboração aos esforços de guerra, destaca-se: "[...] além dessa valiosa contribuição, não posso deixar de mencionar o carinho dispensado pela Cruz Vermelha Brasileira as nossas jovens e abnegadas enfermeiras, que, nos hospitais deste Teatro de Operações, levai, diariamente, aos nossos doentes e feridos, o conforto da presença amiga de mulher patrícia, tão nobre nos seus sentimentos, como decidida na sua ação [...]". 21:24
Na Figura 2 observa-se o embaixador americano Jefferson Caffery junto às enfermeiras da Cruz Vermelha Brasileira logo, se pode inferir tamanha relevância tinha a presença das enfermeiras em comemorações cívicas, tanto nacionais e internacionais, sobretudo ao aliado americano no dia festivo em que se comemorava o Independence Day. A mesma imagem ilustra um artigo publicado em homenagem da Cruz Vermelha Brasileira intitulada como: "Independence Day, data máxima da grande nação irmã do continente - os Estados Unidos da América". 22:4

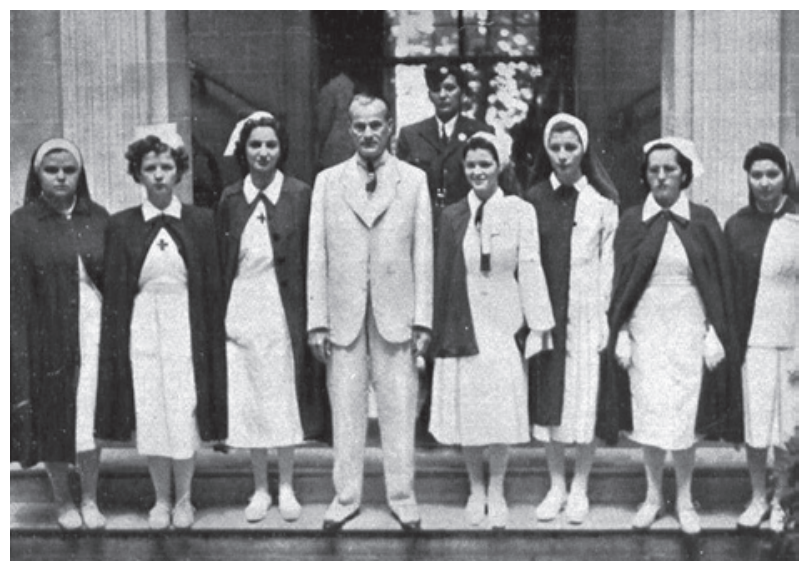

Fonte: Revista da Cruz Vermelha, Agosto, 1943, p. 4.

Figura 2 - Independence Day

$\mathrm{Na}$ análise, percebe-se que o interesse em foco consiste em não deixar de preencher mentalmente o que não se vê ou que cerca aquilo que se vê. ${ }^{23}$ Contudo, tanto na Figura 1, como na Figura 2, têm-se caracteres que expressam categorias simbólicas de exaltação da enfermagem em nível de protagonistas políticos do período, quais sejam: momento de conflito bélico mundial, formação de alianças internacionais e de ideais patriotas exercidos sobre a nação.

Cabe ressaltar, que a fotografia para ser validada deve efetivamente comunicar os sentimentos das coisas que se deseja explorar, comportando-se como apoio a linguagem escrita, sobretudo no campo da propaganda, pois devem vir acompanhadas de legendas verbais com identificação dos personagens, o ano e o lugar do acontecimento; caso contrário, poderse-ia proporcionar decodificações ambíguas ou se tornar um elemento mudo. ${ }^{24}$

\footnotetext{
** Comandante das Forças Expedicionárias Brasileiras nos campos da Itália contra as forças totalitárias do Eixo.
} 
Com a política de americanização do Brasil tornava-se oportuno explorar a mobilização civil, usando como modelo as enfermeiras e a enfermagem, cujas características sustentavam significados como higiene, saúde, abnegação, obediência e servidão atribuídas à identidade profissional no período.

\section{CONSIDERAÇÕES FINAIS}

Os resultados permitem reiterar que as representações da Enfermagem de guerra veiculadas pela imprensa da Cruz Vermelha Brasileira, no bojo da Segunda Guerra Mundial, evidenciaram as enfermeiras como heroínas, legionárias, patrióticas e anjos cuidadores. Entende-se que a enfermagem não somente enfatizava, mas pautava a formação profissional no modelo norte-americano (modelo este da ideologia da americanização), como comprovam as fontes utilizadas, quando estas referenciam a eficiência das enfermeiras dos Estados Unidos da América, como um modelo a ser seguido. Por meio das publicações consultadas, é possível afirmar que a Escola de Enfermagem da Cruz Vermelha Brasileira, instituição formadora da enfermagem de guerra no Brasil, primava por um perfil no qual prevalecia o rigor da disciplina, a pouca idade e resistência física. As imagens da enfermeira de guerra, ao mesmo tempo, evocavam a disciplina militarista peculiar à guerra, e no Brasil aos propósitos de controle social implementado pela política varguista.

Cabe pontuar, que a mobilização das enfermeiras no Brasil, tendo em vista a formação e atuação no front, perpassa os propósitos políticos do Estado Novo e a ideologia dominante, definindo o papel da mulher enfermeira, no âmbito da guerra e no serviço aos filhos da Pátria.

Ademais, o passado da Enfermagem implica não somente evocar a memória do cuidado, mas perceber a trajetória da identidade profissional. A pesquisa histórica na Enfermagem torna-se imperiosa para o desenvolvimento técnico-científico, construção política da identidade coletiva dessa área, na medida em que permite a capacitação de profissionais conscientes, humanizados e críticos em relação ao exercício profissional.

\section{REFERÊNCIAS}

1. Cytrynowicz R. Guerra sem Guerra - a mobilização e o cotidiano em são Paulo durante a segunda guerra mundial. São Paulo (SP): Edusp; 2002.
2. Oguisso T. Origens da prática do cuidar. In: Oguisso $\mathrm{T}$, organizador. Trajetória histórica e legal da enfermagem. Barueri (SP): Manole; 2005. p.3-29.

3. Collière MF. Promover a vida. Lisboa (PT): Printipo; 1989.

4. Sevecenko N. Introdução. O prelúdio republicano, astúcias da ordem e ilusões do progresso. In: Sevecenko N, organizador. História da Vida Privada no Brasil. República: da Belle Époque à Era do Rádio. São Paulo (SP): Companhia das Letras, 1998. p. 7-48.

5. Moreira MCN. A fundação Rockfeller e a construção da identidade profissional de enfermagem no Brasil na Primeira República. Hist Cienc Saúde Manguinhos. 1999 Nov-Fev; 3(1):621-45.

6. Ferreira J. De Roosevelt, mas também de Getúlio: o Serviço Especial de Saúde Pública. Hist Cienc Saúde - Manguinhos. 2007 Out-Dez; 14(4):1425-8.

7. Campos PFS, Oguisso T. A Escola de Enfermagem da Universidade de São Paulo e a reconfiguração da identidade profissional da Enfermagem Brasileira. Rev Bras Enferm. 2008 Nov-Dez; 61(6):892-8.

8. Tota A P. O Imperialismo Sedutor. A americanização do Brasil na Segunda Guerra. São Paulo (SP): Companhia da Letras; 2000.

9. Alves V. O Brasil e a Segunda Guerra Mundial. História de um envolvimento forçado. Rio de Janeiro (RJ): Edições Loyola; 2002.

10. Lynaugh J. Nursing's History: Looking backward and seeing forward. In: Baer ED, D'Antonio P, Rinker S, Lynaugh JE. Enduring issues in American Nursing. New York (US): Springer Publishing Company, Inc.; 2000.

11. Oguisso T, Dutra VO, Campos PFS. Cruz Vermelha Brasileira - Filial Estado de São Paulo: formação em tempos de paz. Barueri (SP): Manole; 2008.

12. Perrot M. Minha História das Mulheres. São Paulo (SP): Contexto; 2007.

13. Padilha MICS, Borenstein MS. O método de pesquisa histórica na enfermagem. Texto Contexto Enferm. 2005 Out-Dez; 14(4):575-84.

14. Sharpe J. A vista de baixo. In: Burke, P, organizador. A escrita da História. Novas perspectivas. São Paulo (SP): UNESP; 1992. p.39-62.

15. Kossoy B. Realidades e ficções na trama fotográfica. Cotia (SP): Ateliê Editorial; 2002.

16. Alves P. Experiência de investigação: pressupostos e estratégias do historiador no trabalho com as fontes. In: Creddo MCS, organizador. Fontes históricas: Abordagens e métodos. Assis (SP): UNESP; 1996. p.33-7

17. Levine, LM. Pai dos pobres: O Brasil e a era Vargas. São Paulo (SP): Companhia das Letras; 2001.

18. Posto 18 da Cruz Vermelha Brasileira. Rev Cruz Vermelha Brasileira. 1943 Ago; 2(1):9. 
19. Simili, IG. Educação e moda na Segunda Guerra Mundial: as propagandas das campanhas da Legião Brasileira de Assistência. Estudos Ibero-Americanos. 2007 jun; 33(1):160-171.

20. Samaritanas e Socorristas de Guerra: Uma enquete. Rev Cruz Vermelha Brasileira. 1943 Ago; 2(2):30.

21. Moraes M. A cooperação da Cruz Vermelha às Forças Expedicionárias Brasileiras. Rev Cruz Vermelha Brasileira. 1944 Mar-Abril; 2(17):24.

22. Independence Day: as homenagens da Cruz Vermelha Brasileira. Rev Cruz Vermelha Brasileira. 1943 Jul; 2(2):4.

23. Guran, M. Linguagem fotográfica e informação. Rio de Janeiro (RJ): Gama Filho; 1999.
24. Leite, MM. Retratos de família. Leituras da fotografia histórica. São Paulo (SP): EDUSP; 1993.

25. Castro Santos LA. A duras penas: estratégias, conquistas e desafios da enfermagem em escala mundial.HistCiencSaúde-Manguinhos. 2008Jan-Mar [acesso 2008 Mai 8]; 15(1). Disponível em http:www. scielo.br/scielo.php?script=sci=arttex\&pid=S010459702008000100002\&ln

26. Bernardes MMR, Lopes GT, Santos TCF. O Cotidiano das Enfermeiras do Exército na Força Expedicionária (FEB) no Teatro de Operações da $2^{\circ}$ Guerra Mundial, na Itália (1942-1945). Latino-am Enfermagem. 2005 maio-jun; 13(3): 314-21.

27. Martins AL, Luca TR. História da Imprensa no Brasil. São Paulo (SP): Contexto; 2008.

E-mail: marciamecone@yahoo.com.br 